CIFRAS DE HOY Rev Chil Salud Pública 2015; Vol 19 (3): 315-316

\section{PERFIL DE EDAD E INGRESOS, SEGÚN PREVISIÓN EN SALUD}

\author{
Profile of AGe AND income ACCORDing to heAlth Cover
}

En un esquema de seguro público que no restringe acceso, mientras los seguros privados pueden usar una batería de opciones para excluir, es obvio pensar en lo que sucederá: el seguro privado se quedará con la población con menor riesgo de enfermar, maximizando sus beneficios.

\section{Beneficiarios por tramo de edad}

En el sistema privado, debido a la tabla de factores, la población asegurada ve aumentado el costo de su plan de salud en varias veces. La natural implicancia es que las ISAPRE concentran a la población menos envejecida y de mayor ingreso. Específicamente, a diciembre 2014, el 90,1\% de la población (FONASA+ISAPRE) mayor a 60 años está cubierta por el seguro público de salud. Independientemente de la edad, la cobertura de FONASA es del $80,3 \%$. A mayor abundamiento, entre los mayores de 60 años, 2.436 .724 personas son cubiertas por FONASA, y solo 267.326 lo son por las ISAPRE.

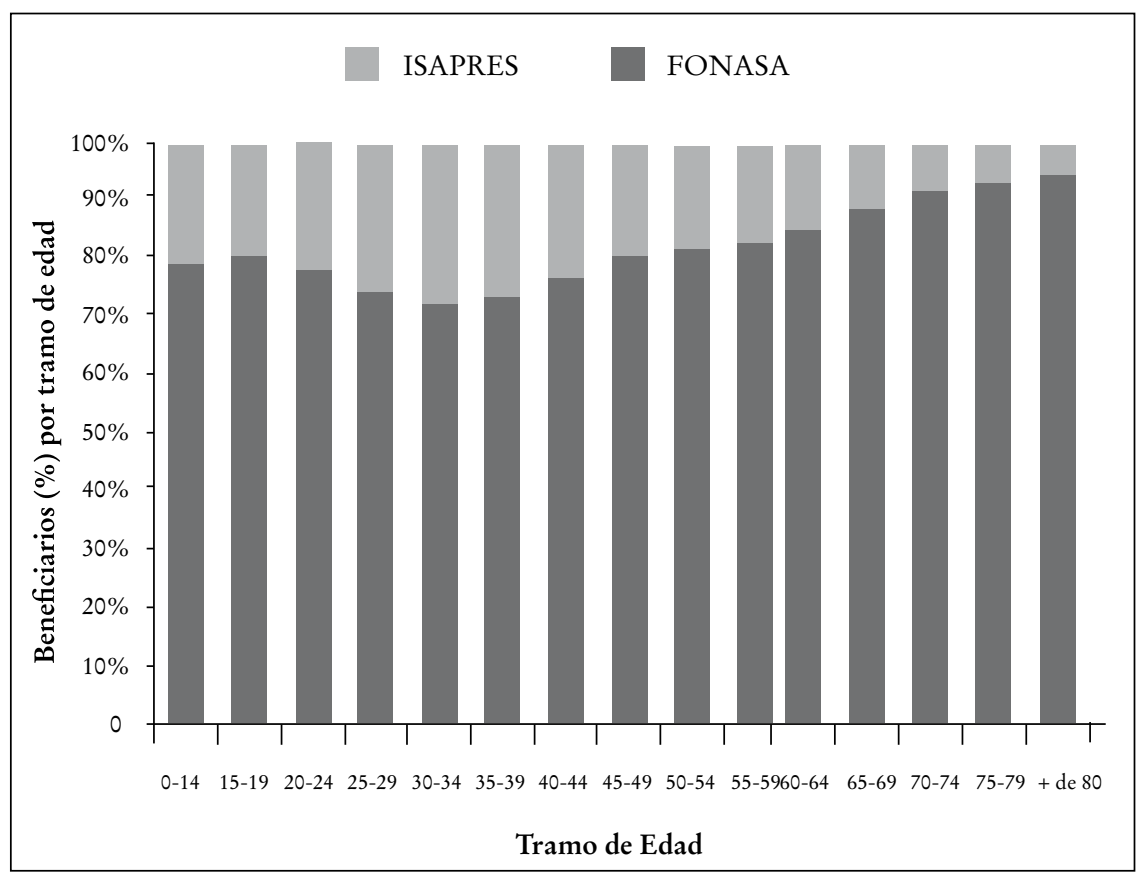

Recibido 11 de septiembre 2014; aceptado 10 de enero 2015 


\section{Beneficiarios por tramo de ingreso}

Específicamente, usamos información de cotizantes $\left(\mathrm{n}^{\circ}\right)$ por tramo de ingreso (a $\$$ dic. 2013).

Los resultados son claros: concentración de usuarios de elevados ingresos en población ISAPRE, mientras FONASA recibe cotizaciones por parte de la población de bajos ingresos. Dada la elevada desigualdad de ingresos en el país, se replica dicha distribución entre los 2 sistemas de salud, con una alta concentración de población bajo los 500 mil pesos.

- En las ISAPRE, de su cartera de cotizantes, el $59 \%$ percibe ingresos supe- riores a 900 mil pesos. Mientras que solo un $8 \%$ de los cotizantes FONASA supera dicho nivel de ingresos.

- Desde otra perspectiva, del grupo de cotizantes con ingresos superiores a 900 mil pesos, el $62 \%$ cotiza en ISAPRE, y el $38 \%$ en FONASA.

- De los 4.4 millones de cotizantes con ingresos inferiores a 500 mil pesos, el $96 \%$ de ellos cotiza en FONASA.

Fuentes: Boletines Estadísticos FONASA, y Superintendencia de Salud.

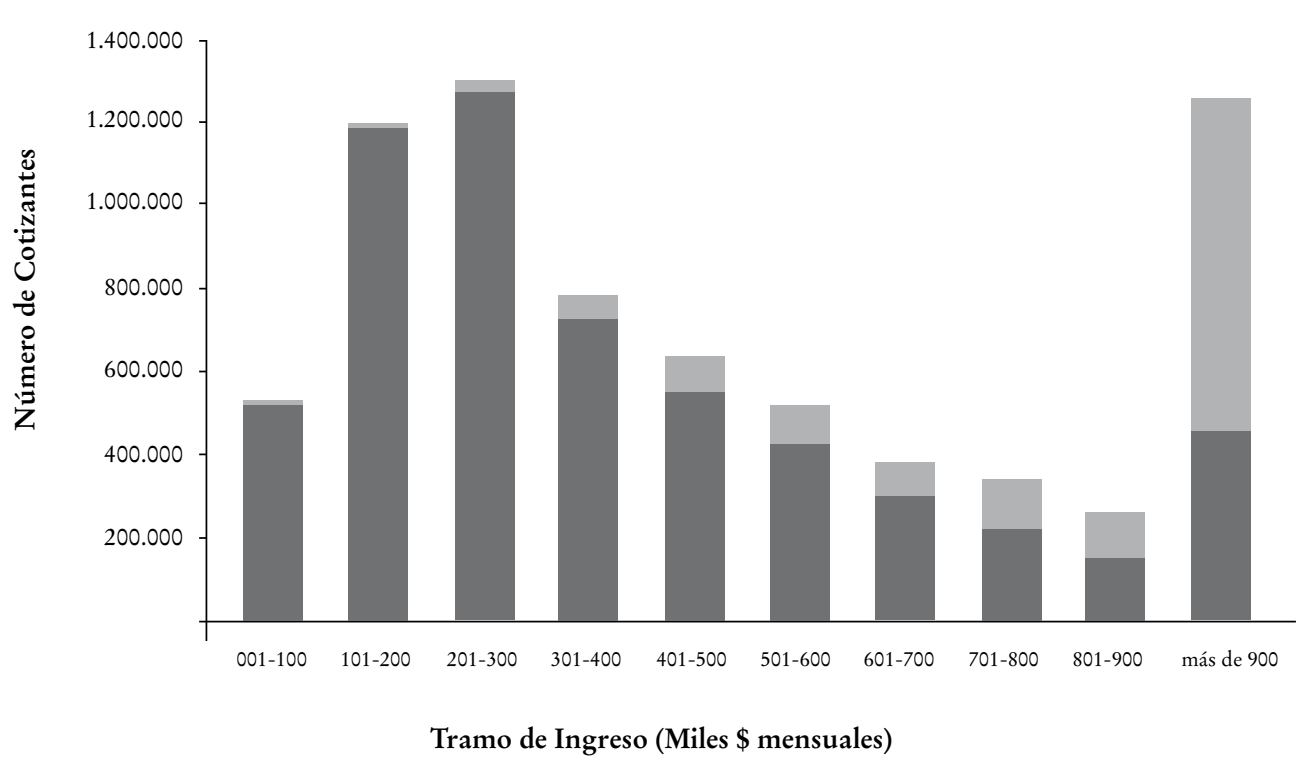

Nota del editor. Bastan solo dos gráficos para confirmar que Chile tiene dos sistemas de salud que no constituyen un "mix" como se ha iterado en muchas ocasiones. El sistema privado es de más alto costo y acoge preferentemente a la población joven y sana. Con el envejecimiento de las poblaciones y el giro epidemiológico hacia mayor prevalencia de enfermedades crónicas, unido a nuestro precario sistema previsional, las personas de tercera edad no pueden solventar las crecientes primas exigidas por las ISAPRE.

En tanto el sistema público no resuelva sus deficiencia -coberturas restrictivas, listas de espera, insuficiencia de médicos, déficit hospitalarios- persistirá la inequidad en materia de salud con un sistema privado de medicina administrada que compite con la atención médica pública. 